\title{
A NOTE ON THREE CASES SHOWING "CROCODILE TEARS" AFTER FACIAL PARALYSIS
}

BY

\author{
L. H. SAVIN \\ LONDON
}

IN 1931 a bricklayer's labourer attended the Royal Eye Hospital complaining that if he ate appetising food, one eye always watered. Two years previously he had had severe facial paralysis on that side, with involvement of taste along the same'side of his tongue. Recovery had been slow in spite of much electrical treatment. On examination the gross movements of the face were found to have recovered fairly completely, but when he whistled or smiled there was considerable twitching and fibrillation elsewhere in the face. On his first visit to the hospital he had just lunched, and the eye did not water when he ate a biscuit. The lower punctum was in good apposition with the globe, and the nasal duct was patent. He was instructed to omit his lunch before the next visit, when eating a biscuit produced copious watering of the eye. It was thought that the phenomenon had some connection with salivation, but the condition remained unexplained and unrelieved.

Search of the literature shewed several reports of the phenomenon, which has been aptly named "crocodile tears" (" Krokodils-tränen," Bogorad, 1928), after the hypocritical tears legendarily ascribed to these reptiles before devouring their victims (see Sir John Maundeville's Travels, c. 1400). Cases have been described by Bogorad (1928), Kaminsky (1926), and Tumarkin (1936). Tumarkin, who reported 13 cases, seems to have given the most reasonable explanation. Normally in Bell's palsy the site of the lesion in the facial nerve is somewhere near the stylomastoid foramen. In more severe cases the nerve may be affected inside the temporal bone in the aqueductus Fallopii. Certain clinical signs may indicate such involvement. If the great superficial petrosal branch from the geniculate ganglion is affected, there may be absence of lacrymation at the first onset of the paralysis instead of the usual mechanical epiphora from orbicularis paralysis. Some at any rate of the secretory fibres of the lacrymal gland pass from the geniculate ganglion of the facial along the great superficial petrosal nerve, and after this has been joined by the great deep petrosal nerve, the secretory fibres pass along the Vidian nerve to Meckel's ganglion. Thence they may take two alterative routes, either passing along the two sphenopalatine nerves, the superior maxillary nerve, the temporomalar (zygomatic) nerve, its communicating branch to the 
lacrymal gland, and so to the lacrymal gland; alternatively orbital branches may connect Meckel's ganglion directly to the lacrymal gland.

Clinical signs are less obvious when the secretory fibres to the parotid are involved. These fibres pass through a communicating branch from the geniculate ganglion to the lesser superficial

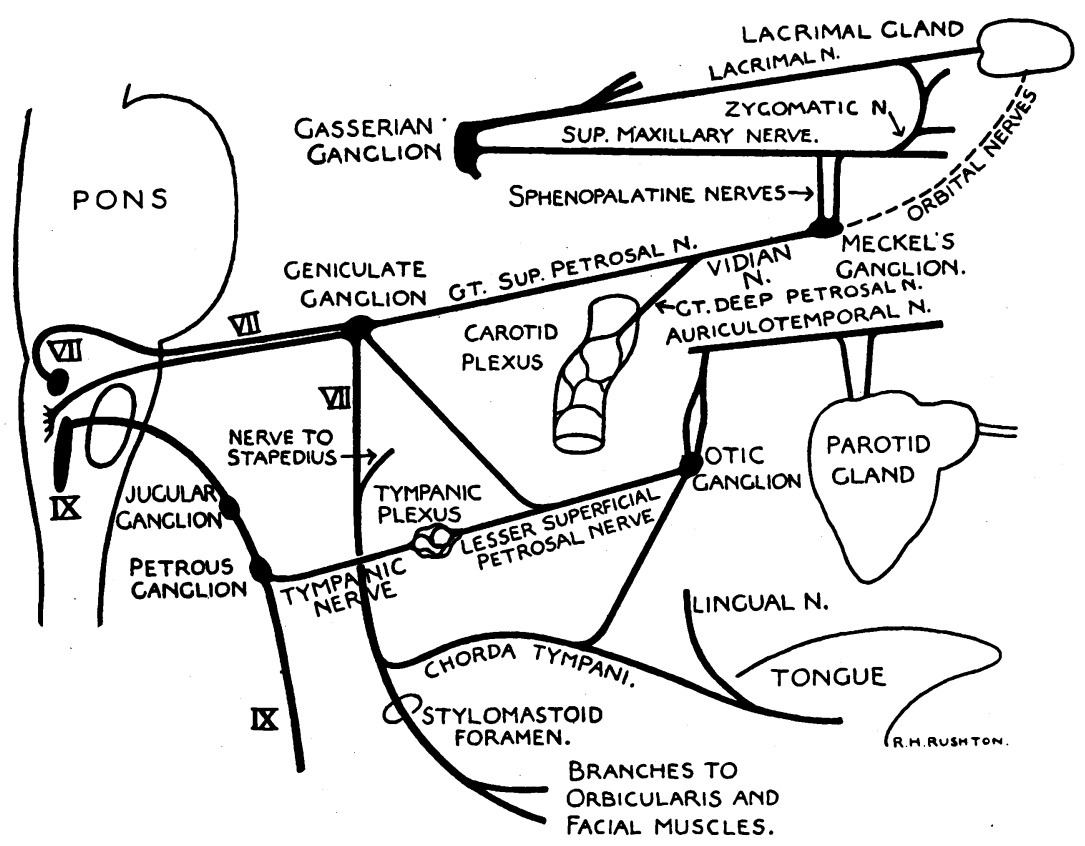

Diagram of the nerves involved in the production of "crocodile tears."

petrosal nerve and the otic ganglion (or alternatively by a branch from the chorda tympani to the otic ganglion). Thence two twigs pass to the auriculo-temporal nerve, through the glandular branches of which the secretory fibres reach the parotid gland.

If the nerve to the stapedius is involved, the patient may complain of hyperacusis, in which certain sounds acquire an unpleasant jarring timbre.

If the chorda tympani is affected, taste will be lost in the anterior two-thirds of the same side of the tongue.

Later when the facial nerve regenerates, Tumarkin states that the newly-growing axis cylinders do not always extend along their original neurilemmal pathways. Hence the phenomenon of synkinesia, where for instance the patient may unconsciously contract the muscles of the nose and mouth, when shutting the eye. Where regenerating parotid secretory fibres accidentally 
pass along the paths to the lacrymal gland, a form of synkinesia will occur in which the patient has to mop his eye when salivation occurs during meals. These " crocodile tears" may produce a troublesome secondary blepharitis. Such lacrymation is distinguishable from the mechanical watering caused by an everted punctum from orbicularis paralysis.

Since reading Tumarkin's papers I have watched for the phenomenon and now report two additional cases.

A barrister's wife developed right facial paralysis in 1925 when she was ayed 29 years. She does not remember if taste was affected in her tongue, though she can describe vividly her initial difficulties in mastication, eating and drinking. Synkinesia is now most obvious in her lower lid which fibrillates when her face moves. Her eye streams with water when she eats; so much so, that she has for years disliked to dine in a restaurant away from home, as she is usually annoyed by some officious waiter who sulicitously asks whether she has something in her eye.

A printer seen recently with " crocodile tears" had right facial paralysis first in 1908, and attended hospital for several years for . electrical treatment. His chorda tympani nerve was evidently affected, as for some years the side of his tongue " felt as if made of indiarubber." His right eye waters so severely on eating, that for years the patient has retired to a secluded spot for his mid-day meal, so as to avoid the chaffing of his fellow workmen. His face is drawn up and contracted on the affected side. Synkinesia is very obvious as fine fibrillary twitching over most of the right side of the face, when he shuts his right eye, whistles, or smiles.

The best method of treatment deserves consideration. The two patients just described were advised to undergo excision of the palpebral portion of the lacrymal gland on the affected side. Both refused on the reasonable grounds that they had become habituated to, and tolerant of their peculiarity. They maintained this attitude when offered an alternative suggested by my oto-rhinological colleagues, Mr. Negus and Mr. Cawthorne. Since the parasympathetic secretory supply to the lacrymal gland passes through Meckel's ganglion, it should prove possible to block temporarily the secretory fibres by cocainization between the posterior end of the middle concha and the lateral wall of the nose, employing a cotton wool-covered probe dipped in cocaine paste or solution. If this simple measure temporarily abolished "crocodile tears" when eating, permanent relief might be expected from blocking Meckel's ganglion with alcohol after the Sluder technique: this would be preferable to the somewhat mutilating procedure of excision of the palpebral portion of the lacrymal gland. Ruskin (1928) has reported lessening of lacrymation after injection of the sphenopalatine ganglion in a patient with obstructed nasal duct. 
A similar patient, in whom the ganglion was recently blocked by Mr. Negus with cocaine, could notice no benefit even of temporary nature. We did not think the experiment conclusive, as there was in this case concurrent conjunctivitis.

I wish to thank Messrs. T. Cawthorne, A. D. Griffith, V. E. Negus, S. Nevin, A. Sorsby, and I. A. Tumarkin for kind advice and explanations.

\title{
REFERENCES
}

BogoraD (1928).-(Cited Kaminsky.) Wratschebnoje djelo (Russ.).

KAMINSKY, S D. (1929).-Deutsche Zeitschr.f. Nervenheilk., Vol. CX, pp 151-160.

RUSKIN, S. L. (1928).-Archiv. of Oto-laryngology, Vol. VII, pp. 351-358

SlUDER, G. (1927). - Nasal Neurology, Headaches and Eye Disorders. H. Kimpton, London, pp. 123-130.

TUMARKIN, I. A. (1936).-Lancet, Vol. I, p. 26.

(1936).-Proc. Roy. Soc. Med., Vol. XXIX, pt. 2, pp. 1685-1€91.

\section{ON THE LOCALISATION OF THE MERIDIAN DETERMINED BY PERIMETRIC MEASUREMENT ON THE OUTSIDE OF THE SCLERA}

\author{
BY \\ Prof. I. AbRamowicz \\ UNIVERSITY EYE CLINIC, WILNO, POLAND
}

THE transfer of the meridian determined by the angle which the plane of the arc of the perimeter forms with the horizontal is not simple. Being done at sight gives only approximate results. Then several authors, Lindner, Zykulenko and others, use for this purpose complicated instruments similar to a goniometer, which

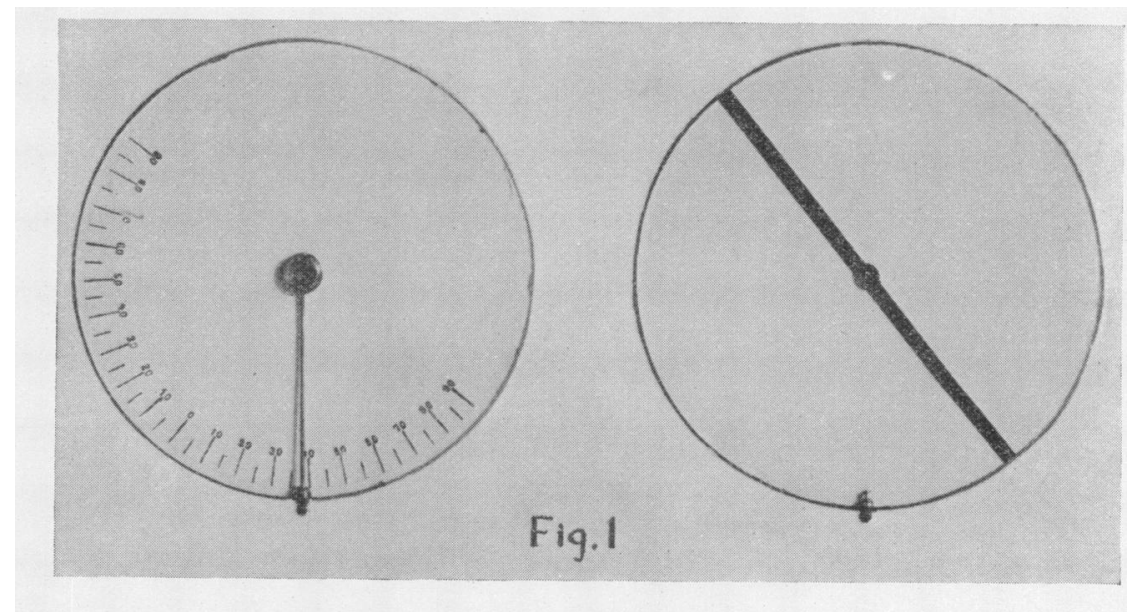

